\title{
Slowly evolving widespread diffuse alimentary tract carcinoma (linitis plastica)
}

\author{
J. Pinto CORREiA, AMÉlia S. BAPtista, AND J. FEliX ANTónio \\ From the Departments of Medicine and Pathology, University Hospital of Santa Maria, and \\ Department of Medicine, Navy Hospital, Lisbon, Portugal
}

Linitis plastica, as a diffuse sclerosing carcinoma, is a slowly progressive, malignant disease (Ewing, 1940). The usual primitive site is the stomach, as the term 'linitis' indicates, but varying degrees of spread along the alimentary tract are encountered (Anderson, 1966). Invasion of the small and large intestine is rare and can lead to confusion with chronic colitis, nonspecific enteritis, and especially with Crohn's disease. About 11 cases of intestinal involvement have been reported (Dixon and Stevens, 1936; Lumb, 1949; Wolf and Marshak, 1963; Fernet, Azar, and Stout, 1965). Histologically the disease is characterized by a striking increase in connective tissue with scanty malignant epithelial cells. Clinically the onset is insidious and the course of the illness slow; the average duration of symptoms before death is one to two years (Bockus, 1963).

The present report is of a case with widespread invasion of the whole alimentary tract from stomach to rectum evolving unusually slowly.

\section{CASE REPORT}

F.M.M.G., a 31-year-old white man, was first seen in November 1963 because of weight loss and dyspepsia.

He was a serving naval officer, previously in good health, except from the ages of 2 to 5 years, when he was treated with bed rest for suspected tuberculosis of the spine. In 1963 he developed dyspepsia, heartburn, and epigastric fulness after meals. He lost $9 \mathrm{~kg}$ in weight in two months. At this time physical examination was negative.

Haemoglobin was $14.8 \mathrm{~g} / 100 \mathrm{ml}$, and the white cell and differential counts were normal. The erythrocyte sedimentation rate (Wintrobe) was $1 \mathrm{~mm}$ in one hour. A radiograph of the dorsal spine showed the changes of old tuberculous lesions.

A barium meal revealed a diffuse filling defect in the entire distal half of the stomach, with no detectable abnormality in the upper intestine (Fig. 1). Gastroscopy was unsuccessful. The patient was symptom-free at the time of discharge.

For the next two years he led an active life but lost a further $5 \mathrm{~kg}$ in weight. In the latter part of 1965 flatulence and anorexia developed, and he had repeated bouts of diarrhoea lasting two to three days, with watery st ools but no blood or mucus. He did not complain of abdominal pain. In the two months before his second admission, in January 1966, the patient himself felt mobile rounded nodules in the left iliac area and right middle quadrant of the abdomen.

At a physical examination in January 1966 he was a pale, thin, afebrile man. Many small lymph nodes were palpable in the inguinal regions. There was a dorsal kyphosis. The liver was hard and enlarged to $5 \mathrm{~cm}$ below the right costal margin and there were two mobile masses the size of nuts in the left iliac fossa and right middle quadrant respectively. No other abnormal physical signs were elicited. The haemoglobin was $13.2 \mathrm{~g} / 100 \mathrm{ml}$, and the white cell and differential counts were normal. Analysis of the urine was negative. The erythrocyte sedimentation rate (Wintrobe) was $5 \mathrm{~mm}$ in one hour. Blood sugar, blood urea, and liver function tests, including serum alkaline phosphatase, were all within normal limits. Wassermann and Kahn tests were negative. An augmented histamine test showed no basal acid secretion, with a $p \mathrm{H}$ of 6.8 , and a 'maximal' acid output of 1.31 m-equiv $\mathrm{HCl} / \mathrm{hr}$, with a $p \mathrm{H}$ of $6 \cdot 8$. A chest radiograph and an ECG were normal. A barium meal and followthrough showed the same diffuse filling defect noted previously (Fig. 2). 'The duodenal cap was normal but there were stenotic lesions in the small bowel, and a barium enema showed these lesions in the caecum, the transverse and descending colon, and in the rectal ampulla also (Fig. 3). Sigmoidoscopy revealed a stenotic ring $12 \mathrm{~cm}$ above the anal sphincter. There was some irregularity of the mucosa but no obvious superficial lesions, although the mucosa bled easily.

A gastric biopsy (Fig. 4) was superficial and showed only plasmocytic infiltration of the lamina propria; tumour cells were not seen. The liver was histologically normal. The rectal biopsy (Fig. 5) showed that the mucosa was thin and contained increased number of mononuclear cells, chiefly plasmocytes. Glands were atrophic and there was a striking increase in fibrous tissue in the lamina propria and in the thickened submucosa. No granulomata were seen in numerous sections. The changes were not conclusive, but were thought to be compatible with an inflammatory process of unknown aetiology.

At this time linitis plastica, Crohn's disease, and tuberculosis were considered as the main possible diagnoses. 


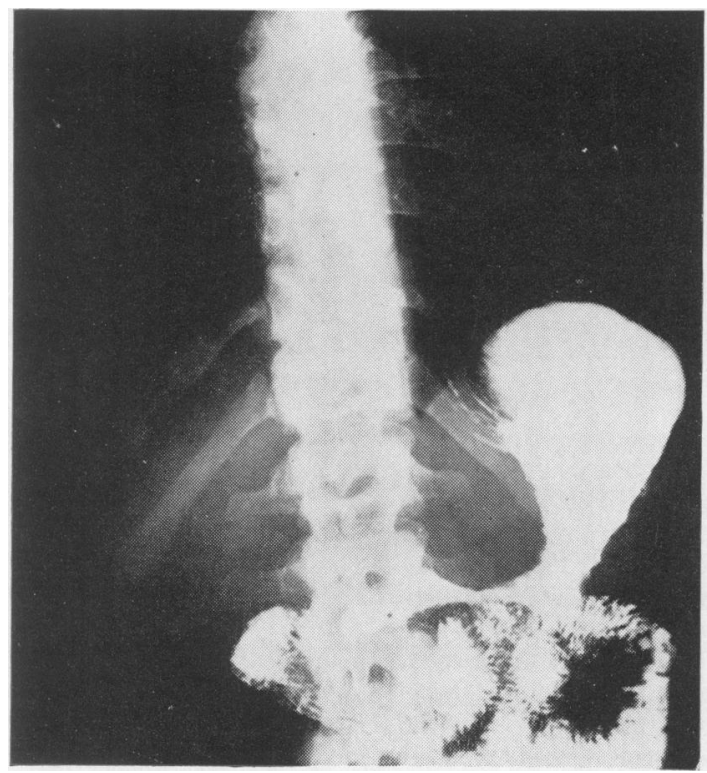

FIG. 1. Barium meal showing diffuse filling defect of the lower half of the stomach (December 1963).

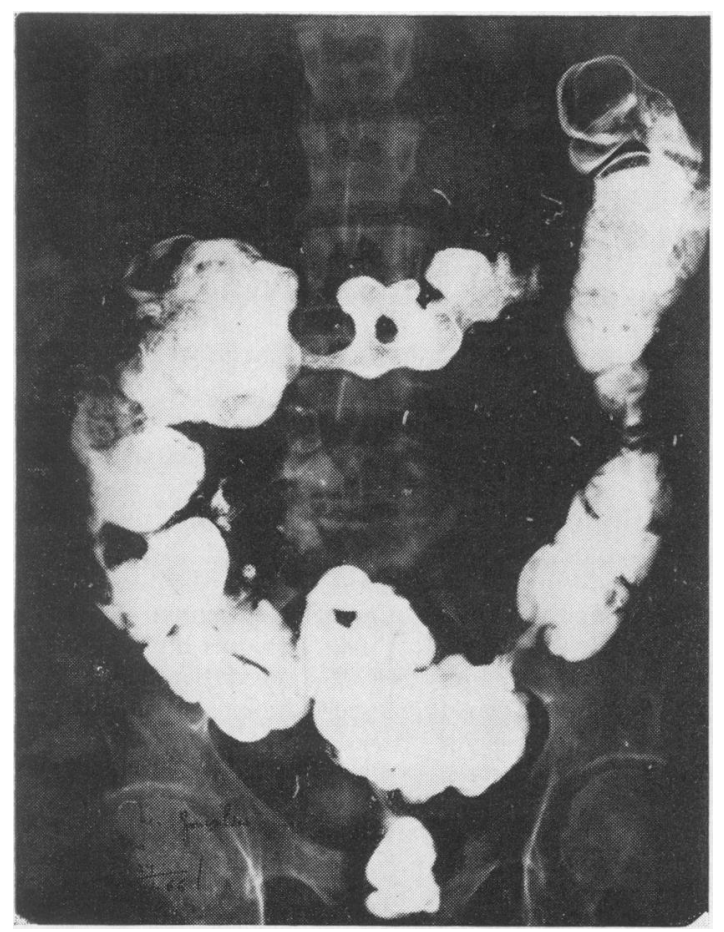

FIG. 3. Barium enema, showing stenotic lesions in the ascending, transverse and descending colon (January 1966).

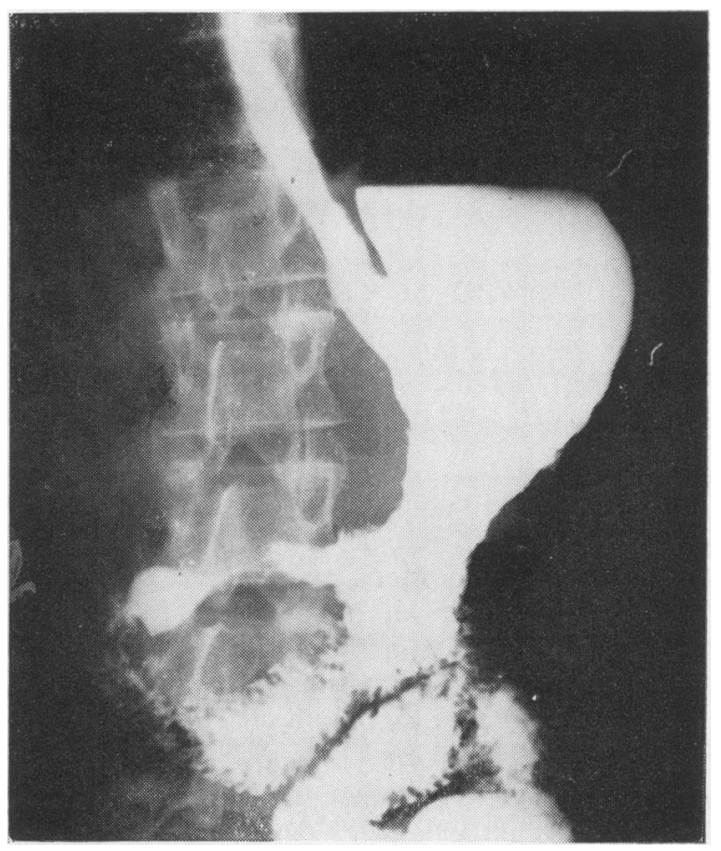

FIG. 2. Same aspect as Fig. I (January 1966).

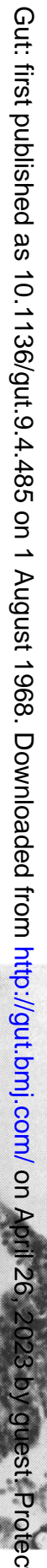

FIG. 4. Very superficial gastric biopsy with plasmocytic infiltra官on of the lamina propria. Haematoxylin and eosin $\times 300$. 


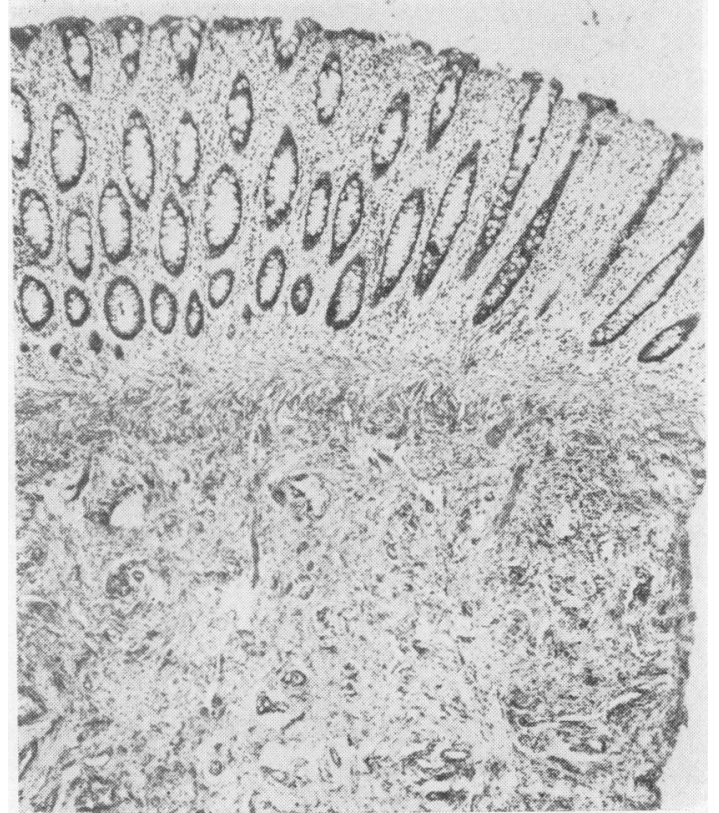

FIG. 5. Rectal biopsy: striking increase of fibrous tissue, chiefly in the submucosa. Haematoxylin and eosin $\times 100$.

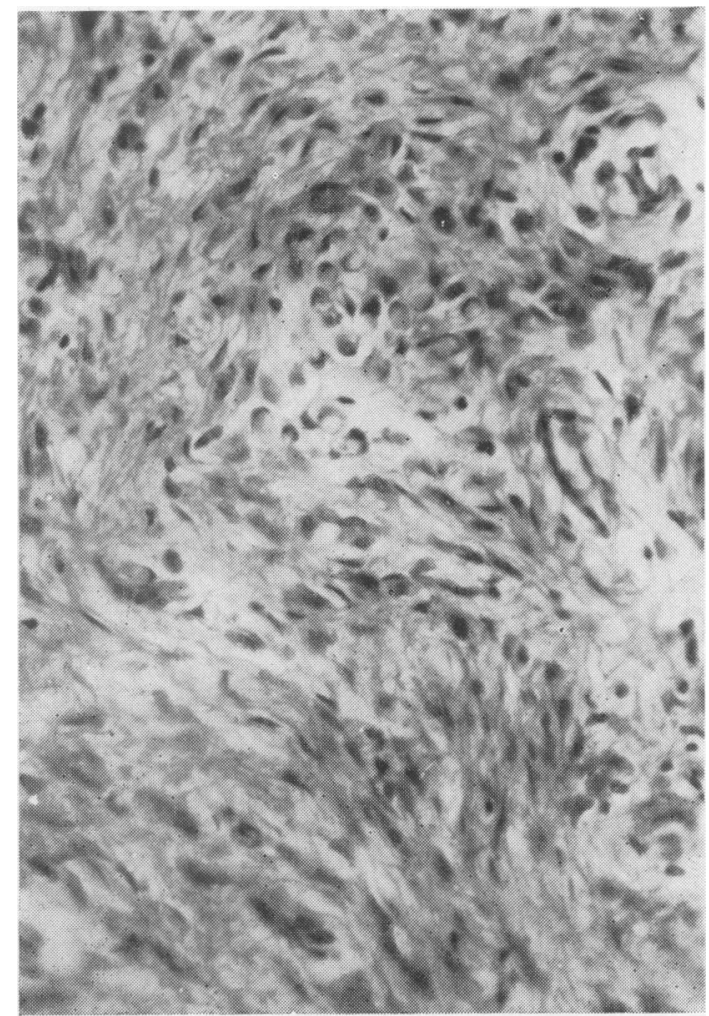

FIG. 6. Surgical biopsy from the omentum: dense fibrous tissue with ovoid tumour cells, some of them with signet-ring appearance. Haematoxylin and eosin $\times 500$.

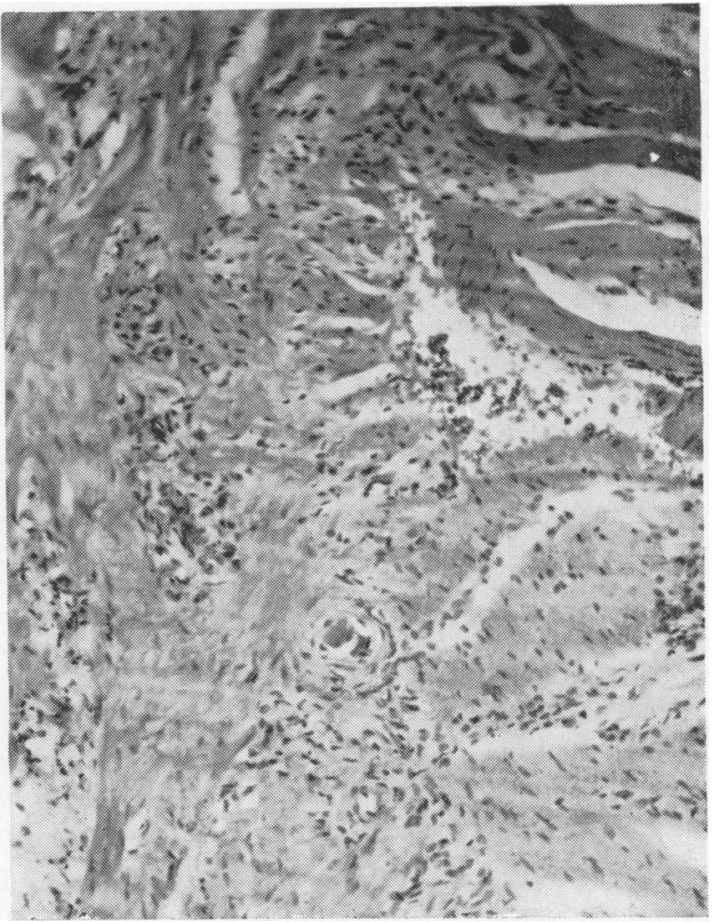

FIG. 7. Intestinal biopsy: tumour cells similar to those of Fig. 6, between the layers of the muscularis propria. Haematoxylin and eosin $\times 250$.

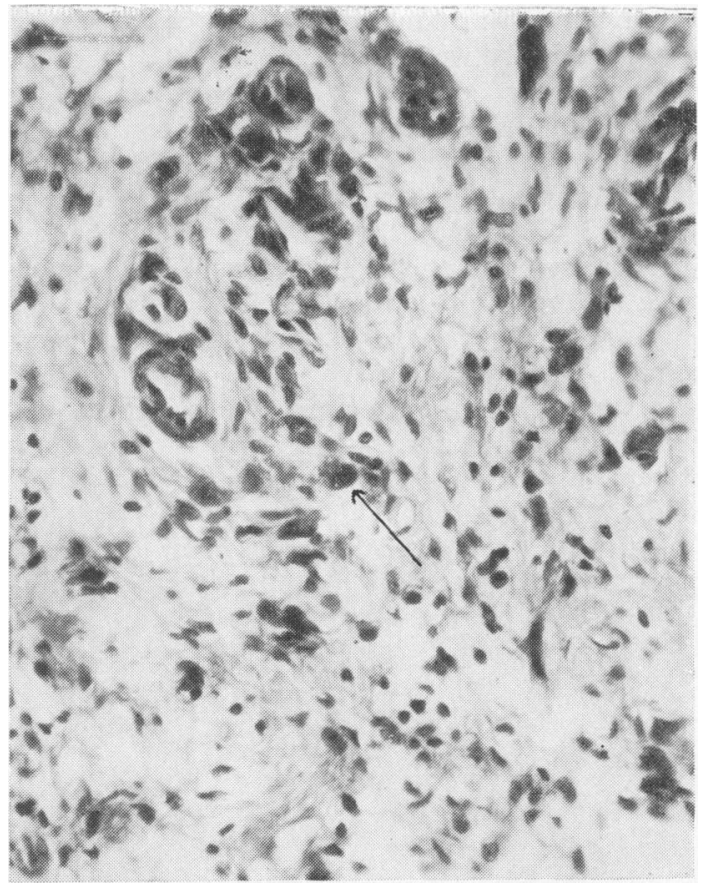

FIG. 8. Rectal biopsy: some of the cells in the submucosa must be considered as atypical (arrow). Haematoxylin and eosin $\times 500$. 
At laparotomy in March 1966 diffuse intramural sclerosis was seen to involve the whole of the stomach, the caecum and the transverse and sigmoid colon. There were pale yellow nodules up to $1 \mathrm{~cm}$ in the omentum and on the serosal surfaces of the gall bladder and small intestine. The liver appeared and felt free of tumour. There was no ascites. No surgical processes were undertaken apart from biopsies from the omentum and from the intestinal nodules.

Histological examination of the omentum (Fig. 6) showed dense hyaline fibrous tissue containing ovoid tumour cells in small groups or singly; most of them were PAS positive and gave positive stains for mucin. Some had a signet-ring appearance. There was no tendency for glands to form. The cells were frequently in the lymphatics. The dense stroma almost obscured the tumour cells. Similar tumour tissue was seen in the serosa and between the layers of the muscularis propria of the intestine, but the latter (Fig. 7) was quite well preserved. Further examination of the original rectal biopsy revealed some atypical cells in the submucosa (Fig. 8). In retrospect these were regarded as malignant.

The patient slowly deteriorated and died in February 1967. No necropsy was performed.

\section{DISCUSSION}

The present case is a striking case of linitis plastica with a known clinical duration of over three years, and a total course which was presumably considerably longer, since lesions were already advanced at the first examination. The course was then longer than the usual one or two years cited by Bockus (1963).

The patient was unusually young, the average age of onset being between 50 and 60 (Fernet et al, 1965).

Laparotomy showed diffuse involvement of stomach and large intestine and widespread peritoneal metastases. Other organs may have been involved also. The case thus corresponds closely to cases of Fernet et al (1965). In the latter cachexia and anaemia were the most important findings, whereas these features were terminal events in our case. In only one of the cases of Fernet were there masses palpable clinically.

Dysproteinaemia, haemorrhagic dyscrasia and liver failure, as reported by Fernet $e t$ al, were not present in our case. Our patient's symptoms were mild and not localized.

The failure to detect tumour cells in a rectal biopsy on the first occasion emphasizes the difficulty of diagnosis due to the abundance of connective tissue and extreme paucity of malignant cells. As in the cases of Fernet et al, there was diffuse invasion of the gastrointestinal tract, with a peculiar distribution; tumour was found in the submucosa and subserosa but was scanty in the muscularis. Such a distribution has been considered to favour longitudinal intramural spread via the lymphatics (Fernet et al, 1965). In the more common forms of gastric adenocarcinoma, intestinal metastases may occur but as nodules rather than diffusely and intestinal metastases from primary growths also do not resemble linitis plastica histologically. In the present case the nodules on the small intestine, omentum, and gall bladder were considered to be peritoneal metastases, distinct from the diffuse sclerosing intramural tumour in stomach and colon.

\section{SUMMARY}

A case of linitis plastica is described. The patient was unusually young. The clinical course lasted over three years and the patient was clinically well until a few months before death. There were no localizing symptoms. At laparotomy diffuse sclerosing tumour was seen in the alimentary tract and there were peritoneal metastases. Histologically scanty cells of an indifferentiated and mucous cell carcinoma were seen in abundant connective tissue. The extent and distribution of tumour were compatible with longitudinal lymphatic spread within the alimentary tract.

\section{REFERENCES}

Anderson, W. A. D. (1966). Pathology, 5th ed., p. 753. Mosby, St. Louis.

Bockus, H. L. (1963). Gastroenterology, 2nd ed., vol. I, p. 781. Saunders, Philadelphia and London.

Dixon, C. F., and Stevens, G. A. (1936). Carcinoma of linitis plastica type involving the intestine. Ann. Surg., 103, 263-272.

Ewing, J. (1940). Neoplastic Diseases, 4th ed., p. 699. Saunders, Philadelphia and London.

Fernet, P., Azar, H. A., and Stout, A. P. (1965). Intramural (tubal) spread of linitis plastica along the alimentary tract. Gastroenterology, 48, 419-424.

Lumb, G. (1949). A case of gastric carcinoma with spread exclusively to the remainder of the bowel and perianal skin. Brit. J. Surg., 37, 41-45.

Wolf, B. S., and Marshak, R. H. (1963). Linitis plastica or diffusely infiltrating type of carcinoma of the colon. Radiology, 81, 502507. 